\title{
Penelitian \\ HUBUNGAN CARA PERSALINAN TERHADAP PREVALENSI KOLONISASI STAPHYLOCOCCUS AUREUS PADA NEONATUS DI RUANG PERINATOLOGI RSIA PURI BETIK HATI
}

\author{
Nadira Rahil Rachmawani ${ }^{1}$, Tri Umiana Soleha ${ }^{2}$ \\ ${ }^{1}$ Fakultas Kedokteran, Universitas Lampung, Indonesia \\ ${ }^{2}$ Departemen Mikrobiologi, Fakultas Kedokteran, \\ Universitas Lampung, Indonesia
}

\begin{abstract}
ABSTRAK
Latar Belakang: Neonatus yang dilahirkan secara normal memiliki kecenderungan terjadinya kolonisasi Staphylococcus aureus yang lebih tinggi pada hidungnya dibandingkan dengan neonatus yang dilahirkan secara perabdominal, hal tersebut dapat terjadi dikarenakan bakteri yang terdapat pada jalan lahir ibunya, sehingga dikhawatirkan tingginya angka kolonisasi bakteri pada neonatus dapat menyebabkan infeksi serius pada neonatus tersebut. Tujuan penelitian ini adalah untuk melihat hubungan cara persalinan terhadap prevalensi kolonisasi Staphylococcus aureus pada neonatus di Ruang Perinatologi RSIA Puri Betik Hati.

Metode: Penelitian ini merupakan penelitian analitik dengan pendekatan cross sectional menggunakan data primer dengan pemeriksaan laboratorium. Pengambilan sampel dilakukan di ruang Perinatologi RSIA Puri Betik Hati tahun 2017. Sampel diambil menggunakan consecutive sampling dengan total sampel ialah 62 sampel yang memenuhi kriteria inklusi dan kriteria eksklusi. Analisis data menggunakan Chi Square dengan $\alpha=0,05$ dan $\mathrm{Cl}=95 \%$.

Hasil: Hasil dari penelitian ini ialah terdapat hubungan cara persalinan terhadap prevalensi kolonisasi Staphylococcus aureus pada neonatus di Ruang Perinatologi RSIA Puri Betik Hati dengan nilai $\mathrm{p}=0,001$ dimana kolonisasi bakteri lebih banyak ditemukan pada neonatus yang dilahirkan secara normal.
\end{abstract}

SImpulan: Cara melahirkan mempengaruhi prevalensi kolonisasi Staphylococcus aureus pada neonatus.

Kata Kunci: Cara melahirkan, neonatus, Staphylococcus aureus

\section{ABSTRACT}

Background. Neonates with normal parturitition have a tendency to colonized by Staphylococcus aureus higher than neonates with perabdominal parturitition, this case may occur due to the bacteria present in the mother's birth canal. Staphylococcus aureus colonization can lead to serious infections. The purpose of this study was to examine the relationship of types of parturitition to the prevalence of colonization of Staphylococcus aureus in neonates.

Methods. This is an analytical research with cross sectional approach using primary data with laboratory examination. Sampling was conducted in the perinatology room of RSIA Puri Betik Hati in 2017 and was taken using consecutive sampling with total sample is 62 samples that fulfill the inclusion criteria and exclusion criteria.

Results. The result of this research is, there is relation between types of parturitition and the prevalence of colonization of Staphylococcus aureus in neonates in Perinatology Room of RSIA Puri Betik Hati with $p$ value $=0,001$ where bacterial colonization is more common in neonates who are born with normal parturitition.

Conclusion. The types of parturitition affects the prevalence of colonization of Staphylococcus aureus in neonates.

Keywords: neonates, Staphylococcus aureus, types of parturitition 


\section{PENDAHULUAN}

Penyebab penting morbiditas dan mortalitas pada bayi salah satunya ialah infeksi. Penyakit infeksi pada bayi baru lahir menyebabkan kematian akibat sepsis di wilayah Asia Tenggara dilaporkan oleh World Health Organization (WHO) sekitar 2,9 per 1000 $\mathrm{KH}$, khususnya di Indonesia, kasus ini menempati angka kematian neonatal tertinggi yaitu 13,5 per $1000 \mathrm{KH}^{1}$ Kejadian infeksi neonatal ini dapat dihubungkan dengan angka prematuritas, pelaksanaan persalinan perawatan prenatal, dan kondisi lingkungan di ruang perawatan. Selain disebabkan oleh faktor-faktor tersebut, infeksi neonatal juga dapat terjadi secara intrauterin maupun secara intrapartum yaitu selama proses persalinan, diduga infeksi dapat terjadi secara ascendens bila terjadi partus lama dan ketuban pecah dini, lalu infeksi dapat terjadi setelah proses melahirkan selesai (pasca partum) akibat sumber infeksi dari lingkungan luar setelah lahir. ${ }^{2}$

Salah satu bakteri penyebab infeksi pada bayi baru lahir Staphylococcus aureus dimana bakteri tersebut berkolonisasi di kulit dan mukosa manusia dan beberapa hewan. ${ }^{3}$ Staphylococcus aureus bersifat patogen oportunistik dan merupakan bakteri flora normal pada manusia. Staphylococcus aureus dapat menyebabkan infeksi serius dengan tanda-tanda yaitu peradangan, nekrosis, dan pembentukan abses. ${ }^{4}$

Beberapa faktor yang dapat memicu terjadinya kolonisasi Staphylococcus aureus terutama pada bayi baru lahir, salah satunya yaitu proses melahirkan dan perawatan antenatal. ${ }^{5}$ Penelitian terdahulu menyebutkan bahwa bayi yang dilahirkan dari ibu yang memiliki karier Staphylococcus aureus di daerah perineumnya dan dilahirkan dengan persalinan normal memiliki kolonisasi Staphylococcus aureus lebih tinggi, yakni sebesar $41,5 \%$ dibandingkan dengan bayi yang dilahirkan dengan operasi sectio caesarea atau perabdominal yang hanya $15,4 \% .6,7$

Berdasarkan latar belakang tersebut, peneliti tertarik untuk melakukan penelitian mengenai hubungan antara cara persalinan terhadap prevalensi kolonisasi
Staphylococcus aureus pada neonatus di ruang Perinatologi RSIA Puri Betik Hati, Bandar Lampung. Penelitian ini bertujuan untuk mengetahui hubungan cara persalinan terhadap prevalensi kolonisasi Staphylococcus aureus pada neonatus di ruang Perinatologi RSIA Puri Betik Hati, Bandar Lampung yaitu dengan membandingkan jumlah neonatus dengan kolonisasi Staphylococcus aureus yang dilahirkan secara normal daengan neonatus yang dilahirkan secara perabdominal.

\section{METODE}

Penelitian ini merupakan penelitian analitik dengan pendekatan cross sectional. Pengambilan sampel dilakukan di Ruang Perinatologi RSIA Puri Betik Hati Bandar Lampung, sedangkan pemeriksaan dilakukan di Laboratorium Mikrobiologi Fakultas Kedokteran Universitas Lampung pada bulan September-November 2017 dimana telah mendapat persetujuan etik dengan nomor 4181/UN26.8/DL/2017.

Variabel bebas dalam penelitian ini adalah cara persalinan secara normal dan perabdominal sedangkan Variabel terikat dalam penelitian ini adalah kolonisasi Staphylococcus aureus dari swab hidung neonatus.

Teknik pengambilan sampel yang digunakan dalam penelitian ini adalah consecutive sampling. Pada consecutive sampling, semua subjek yang datang dan memenuhi kriteria pemilihan akan dimasukkan dalam penelitian sampai jumlah sampel yang diperlukan sudah terpenuhi. Adapun jumlah sampel yang akan diambil adalah menggunakan rumus:

$$
\begin{gathered}
n=\left[\frac{\mathrm{Z} \alpha \sqrt{2 P Q}+Z \beta \sqrt{P_{1} Q_{1}+P_{2} Q_{2}}}{\left(P_{1}-P_{2}\right)}\right]^{2} \\
n=\left[\frac{1,96 \sqrt{2 x 0,6 x 0,4}+0,20 \sqrt{0,7 x 0,3+0,5 x 0,5}}{(0,2)}\right]^{2}=56
\end{gathered}
$$

$\mathrm{N}=$ Jumlah sampel minimal

$\mathrm{Z} \alpha \quad=$ Derivat baku alfa $(1,96$; de-

ngan menggunakan $\alpha=0,05)$

$Z \beta=$ Derivat baku beta $(0,84$; dengan menggunakan $\beta=$ $0,20)$

$\mathrm{P} 1-\mathrm{P} 2$ = Selisih proporsi minimal yang dianggap bermakna $(0,2)$

P1 = Proporsi pada kelompok uji, atau kasus $=0,2+0,5=0,7$ 


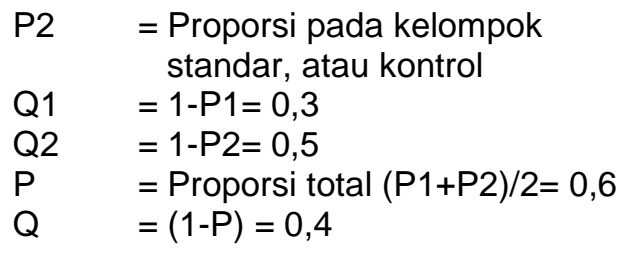

Jadi berdasarkan perhitungan, jumlah sampel pada penelitian ini adalah \pm 56 orang, untuk menghindari hilang pengamatan maka jumlah sampel ditambah $10 \%$ sehingga dalam penelitian ini banyak sampel yang dibutuhkan ialah 62 orang.

Adapun sampel penelitian ini berasal dari neonatus di ruang Perinatologi RSIA Puri Betik Hati, dengan kriteria:

1. Kriteria Inklusi

a. Neonatus yang sehat dan berada di ruang Perinatologi RSIA Puri Betik Hati.

b. Neonatus yang dirawat $<48$ jam.

2. Kriteria Eksklusi
a. Neonatus dengan BBLR dan asfiksia.
b. Neonatus yang dirawat lebih dari sama dengan 48 jam.
c. Neonatus dari ibu yang melahirkan secara perabdominal dengan indikasi pemberian antibiotik profilaksis.
d. Neonatus dari ibu yang melahirkan dengan persalinan normal dengan komplikasi.

Alat-alat yang dipakai adalah alatalat yang biasa dipakai di Laboratorium Mikrobiologi, seperti lemari pengeram (inkubator), pinset, bunsen, tabung reaksi, ose, cawan petri, lidi kapas steril, lampu bunsen, gelas objek, cover glass, mikroskop serta peralatan lain yang lazim digunakan di laboratorium mikrobiologi.

Bahan yang dipakai dalam penelitian antara lain isolat bakteri swab hidung dari neonatus yang berada di ruang Perinatologi RSIA Puri Betik Hati, Nutrient broth, Nutrient agar, media Mannitol Salt Agar (MSA), bahan pewarnaan gram (kristal violet, iodin, alkohol 70\%, safranin), aquades, agar darah, dan bahan lain yang lazim digunakan di laboratorium mikrobiologi.

Kemudian dilakukan pengambilan dan isolasi spesimen Staphylococcus aureus dimana ssolat diambil dari neonatus yang telah memenuhi kriteria inklusi dan eksklusi, lalu dilakukan pencatatan data cara melahirkan neonatus tersebut melalui data sekunder, yaitu rekam medis. Lalu peneliti melakukan informed consent kepada orang tua dari neonatus yang memenuhi kriteria yang apabila disetujui, orang tua akan menandatangani lembar persetujuan. Setelah itu, dilakukan pengambilan isolat dengan cara swab pada bagian nares anterior dengan menggunakan lidi kapas steril yang telah dibasahi dengan nutrient broth. Isolat kemudian ditanam pada media nutrient agar, lalu ditutup menggunakan seal microfilm dan alumunium foil. Isolat dibawa ke Laboratorium FK Universitas Lampung menggunakan cool box dan dry ice untuk menjaga suhu selama perjalanan, lalu diinkubasi di laboratorium pada suhu $37^{\circ} \mathrm{C}$ selama 24 jam.

Lalu dilakukan identifikasi mikroorganisme. Identifikasi bakteri dilakukan dengan langkah berikut:

1. Makroskopis

Identifikasi secara makroskopis dengan menggunakan pengamatan untuk melihat morfologi koloni. Warna koloni putih susu atau krem dan dipastikan lebih lanjut pada pemeriksaan mikroskopis.

2. Mikroskopis

Bakteri diidentifikasi dengan menggunakan pewarnaan gram untuk melihat bentuk sel dan sifat bakteri terhadap warna. Langkah kerja pewarnaan gram:

1. Gelas objek dibersihkan dengan alkohol $70 \%$ dan difiksasi dengan cara dilewatkan beberapa kali pada nyala api bunsen selama beberapa saat.

2. Ose dipanaskan dengan cara di lewatkan di atas api bunsen, kemudian ditunggu hingga sedikit dingin.

3. Olesan tipis isolat bakteri dibuat dengan jarum ose secara septis pada gelas objek.

4. Spesimen difiksasi dengan melewatkannya di atas api bunsen sebanyak tiga kali.

5. Spesimen diletakkan pada rak pewarna. Kristal violet (gram $A=$ cat utama) diteteskan pada gelas objek sampai menutupi seluruh sediaan. Kemudian didiamkan 
selama 60 detik, lalu dicuci dengan air mengalir secara perlahan.

6. Spesimen ditetesi dengan larutan iodin (gram B = larutan mordan), dibiarkan selama 60 detik, lalu dicuci pada air mengalir hingga tetesan menjadi bening.

7. Dekolorisasi spesimen dilakukan dengan ditetesi etil alkohol 95\% (gram C) sedikit demi sedikit selama 20-30 detik atau sampai terlihat adanya warna yang luntur.

8. Spesimen dialiri dengan air selama beberapa detik untuk menghentikan aktivitas dekolorisasi.

9. Spesimen ditetesi dengan safranin selama 20-30 detik, kemudian dicuci dengan air mengalir selama beberapa detik untuk menghabiskan sisa-sisa cat sampai bersih dan dikeringkan.

10. Hasil pewarnaan diamati dengan mikroskop untuk melihat bentuk sel dan sifat bakteri terhadap zat warna.

11. Apabila bakteri terlihat berwarna ungu, menandakan bahwa bakteri tersebut bakteri gram positif. Apabila bakteri terlihat berwarna merah, menandakan bahwa bakteri tersebut bakteri gram negatif.

Bakteri yang telah tumbuh selanjutnya diisolasi dengan cara ditanamkan dalam agar darah dan Mannitol Salt Agar (MSA). Agar darah digunakan untuk mengidentifikasi bakteri gram positif diinkubasi selama 24 jam pada suhu $37^{\circ} \mathrm{C}$ dimana ditemukan hasil positif bila ditemukan zona hemolisin/zona jernih disekitar koloni yang tumbuh di media tersebut. Koloni yang tumbuh pada agar darah selanjutnya ditanamkan pada media Mannitol Salt Agar (MSA) kemudian didiamkan 2-5 menit agar bakteri meresap ke dalam media kemudian diinkubasi pada suhu $37^{\circ} \mathrm{C}$ selama 24 48 jam. Apabila media berubah menjadi warna kuning, maka bakteri tersebut dapat tumbuh dalam suasana garam serta dapat memfermentasikan manitol. Perubahan warna pada media menandakan bakteri tersebut adalah Staphylococcus aureus.

Selain itu juga dilakukan uji biokimia, untuk bakteri gram positif akan dilakukan uji biokmia antara lain yaitu uji katalase. Uji ini dilakukan dengan cara koloni diletakkan pada gelas objek sebanyak satu ose kemudian cairan $\mathrm{H}_{2} \mathrm{O}_{2}$ diteteskan pada gelas objek tersebut. Hasil positif apabila terdapat gelembung udara yang menandakan bakteri yang berkembang adalah Staphylococcus sp. dan hasil negatif apabila tidak terdapat gelembung udara yang menandakan bakteri yang berkembang adalah Streptococcus $s p$.

\section{HASIL PENELITIAN}

Responden dalam penelitian ini berjumlah 62 orang, dengan rincian 31 neonatus dilahirkan dengan cara persalinan normal dan 31 neonatus dilahirkan dengan cara persalinan perabdominal. Neonatus yang dilahirkan secara perabdominal ialah yang bukan persalinan dengan indikasi pemberian antibiotik atau karena terjadi komplikasi pada saat persalinan normal. Karakteristik responden pada penelitian ini dapat dilihat pada tabel berikut.

Tabel 1. Karakteristik Subyek Penelitian.

\begin{tabular}{llll}
\hline \multicolumn{1}{c}{ Karakte-ristik } & & Freku-ensi & Per-sen (\%) \\
\hline Usia ibu & $20-35$ & 57 & 91,9 \\
& $>35$ & 5 & 8,1 \\
\hline Cara persalinan & Persalinan normal & 31 & 50
\end{tabular}


Persalinan

perabdominal

\begin{tabular}{llll}
\hline IMD & IMD & 58 & 93,5 \\
& Tidak IMD & 4 & 6,5 \\
& & & 50 \\
\hline Usia bayi & 0 hari & 31 & 50 \\
& $1-2$ hari & 31 & 93,5 \\
\hline Berat badan bayi & $2500-3800$ & 58 & 6,5 \\
& $>3800$ & 4 & \\
\hline
\end{tabular}

Tabel 2. Distribusi Frekuensi cara persalinan dan kolonisasi Staphylococcus aureus pada neonates.

\begin{tabular}{|c|c|c|}
\hline Variabel & Frekuensi & Presentase (\%) \\
\hline \multicolumn{3}{|l|}{ Cara persalinan } \\
\hline Persalinan normal & 31 & 50 \\
\hline Persalinan perabdominal & 31 & 50 \\
\hline \multicolumn{3}{|l|}{$\begin{array}{l}\text { Kolonisasi Staphylococcus } \\
\text { aureus }\end{array}$} \\
\hline Positif & 17 & 27,4 \\
\hline Negatif & 45 & 72,6 \\
\hline
\end{tabular}

Kemudian dilakukan analisis univariat yaitu analisis yang bertujuan untuk mendeskripsikan karakteristik setiap variabel penelitian. Setelah dilakukan analisis data secara univariat, didapatkan hasil frekuensi cara persalinan dan kolonisasi Staphylococcus aureus pada neonatus pada tabel 2:

Lalu dilanjutkan analisis bivariat yaitu analisis yang dilakukan untuk mengetahui keterkaitan antara dua variabel dan menguji ada atau tidaknya pengaruh antara variabel bebas dan variabel tergantung. Analisis data ini bertujuan untuk mengetahui hubungan antara cara persalinan terhadap prevalensi kolonisasi Staphylococcus aureus pada neonatus di ruang Perinatologi Rumah Sakit lbu dan Anak Puri Betik Hati Bandar Lampung. Setelah dilakukan analisis data maka didapatkan hasil yang disajikan dalam tabel 3: 
Tabel 3. Hubungan antara cara persalinan terhadap prevalensi kolonisasi Staphylococcus aureus pada neonatus di ruang Perinatologi Rumah Sakit Ibu dan Anak Puri Betik Hati Bandar Lampung.

\begin{tabular}{lll}
\hline Cara persalinan & $\begin{array}{l}\text { Kolonisasi bakteri Total } \\
\text { pada neonatus }\end{array}$ & $p$ value
\end{tabular}

$(+) \quad(-)$

\begin{tabular}{lcccc}
\hline Persalinan normal & 16 & 15 & 31 & 0,001 \\
\hline Persalinan perabdominal & 1 & 30 & 31 & \\
\hline Total & 17 & 45 & 62
\end{tabular}

Hasil uji statistik dengan menggunakan uji Kai Kuadrat (Chi Square) didapatkan nilai $p=0,001$, dikarenakan nilai $\mathrm{p}<0,05$ maka dapat disimpulkan bahwa terdapat hubungan

\section{PEMBAHASAN}

Hasil penelitian menggambarkan untuk cara persalinan didapatkan frekuensi yang sama yaitu $50 \%$ ibu dengan cara persalinan normal dan $50 \%$ ibu dengan cara persalinan perabdominal. Untuk kepentingan penelitian ini, sampel untuk variabel cara melahirkan diambil sama rata baik persalinan secara normal maupun perabdominal, hal ini dimaksudkan untuk melihat perbedaan hasil kolonisasi Staphylococcus aureus pada neonatus dari masing-masing ibu baik yang melahirkan secara normal maupun yang melahirkan secara perabdominal.

Cara persalinan dalam penelitian ini dipilih dua jenis cara persalinan yaitu cara persalinan secara pervaginam dimana persalinan ini melalui jalan lahir ${ }^{8}$ serta cara persalinan sectio caesarea yaitu persalinan melalui prosedur bedah sebagai bentuk melahirkan anak sehingga janin yang akan dilahirkan tidak melalui jalan lahir. ${ }^{9}$

Dari total 62 sampel variabel kolonisasi Staphylococcus aureus pada neonatus, didapatkan yaitu 17 sampel neonatus yang positif terkolonisasi Staphylococcus aureus. Kolonisasi antara cara persalinan terhadap prevalensi kolonisasi Staphylococcus aureus pada neonatus di ruang Perinatologi Rumah Sakit lbu dan Anak Puri Betik Hati Bandar Lampung.

Staphylococcus aureus tepatnya dibagian nares anterior dari neonatus, hal ini sesuai dengan penelitian oleh Sollid tahun 2014 dan Almeida tahun 2014 yang mengatakan Staphylococcus aureus merupakan kuman yang berkolonisasi di banyak bagian tubuh salah satunya pada nares anterior. ${ }^{10,11}$

Jumlah neonatus dengan kolonisasi Staphylococcus aureus yang dilahirkan dengan cara persalinan normal ialah berjumlah 16 neonatus dari 31 sampel, dan jumlah neonatus dengan kolonisasi Staphylococcus aureus yang dilahirkan dengan cara persalinan perabdominal ialah 1 neonatus dari 31 sampel. Dari hasil tersebut dapat dilihat bahwa terdapat perbedaan jumlah neonatus yang terkolonisasi dari dua jenis cara persalinan, sehingga dapat dikatakan bahwa cara persalinan mempengaruhi prevalensi kolonisasi Staphylococcus aureus pada neonatus, hal ini dibuktikan pada uji statistik analisis bivariat yang dilakukan dengan menggunakan uji statistik Kai Kuadrat (Chi Square), dimana didapatkan hasil yaitu $p$ value sebesar 0,001 . Hal ini menunjukkan nilai $\mathrm{p}$ lebih kecil daripada taraf signifikansi yang diharapkan yaitu $\alpha=0,05$ sehingga didapatkan hasil penelitian yang 
bermakna. Dengan demikian, hipotesis null ditolak dan hipotesis mengenai adanya hubungan antara cara persalinan terhadap prevalensi kolonisasi Staphylococcus aureus pada neonatus di ruang Perinatologi Rumah Sakit Ibu dan Anak Puri Betik Hati Bandar Lampung dapat diterima.

Penelitian serupa juga dilakukan oleh Puspitasari Notohatmodjo pada tahun 2011, dimana pada penelitian tersebut didapatkan $p=0,006$ dimana cara persalinan normal merupakan faktor risiko penting untuk terjadinya kolonisasi Staphylococcus aureus pada neonatus. ${ }^{12}$

Pada penelitian oleh Bourgeois tahun 2010 menyebutkan bahwa neonatus berisiko lebih besar terkolonisasi Staphylococcus aureus apabila neonatus tersebut dilahirkan dengan cara persalinan normal, dimana jalan lahir merupakan faktor penting terjadi transmisi infeksi pada persalinan normal. Ibu dengan kolonisasi Staphylococcus aureus pada tubuhnya, terutama pada daerah perineum, dapat menjadikan bayi yang dilahirkannya ikut terolonisasi Staphylococcus aureus, dimana terjadi transmisi secara vertikal dari ibu ke bayi melalui jalan lahir. Sedangkan, ibu yang melahirkan secara perabdominal menurunkan risiko terjadinya kolonisasi Staphylococcus aureus pada neonatus yang dilahirkannya, dikarenakan bayi dilahirkan tidak melalui jalan lahir sehingga kemungkinan bayi terkolonisasi Staphylococcus aureus sangat kecil. Hal ini dibuktikan dalam penelitian tersebut bahwa neonatus yang dilahirkan dengan persalinan normal memiliki kolonisasi Staphylococcus aureus lebih tinggi, yakni $41,5 \%$ dibandingkan dengan bayi yang dilahirkan secara perabdominal yang hanya $15,4 \%{ }^{6}$

Penelitian oleh Dahlman tahun 2017 menyebutkan bahwa perineum merupakan tempat tersering untuk terjadinya kolonisasi Staphylococcus aureus, dimana ibu dengan kolonisasi Staphylococcus aureus pada perineumnya dapat disebut sebagai karier Staphylococcus aureus, hal tersebut dikaitkan dengan kebersihan dari ibu itu sendiri. Sehingga dapat disimpulkan, sanitasi dan higiene berpengaruh untuk terjadinya kolonisasi pada daerah perineum khususnya seorang ibu, dikarenakan perineum bisa menjadi tempat berkembang biak yang nyata bagi mikroorganisme ini dan sumber infeksi yang potensial. ${ }^{13}$

Selain itu, penelitian ini tidak sejalan dengan penelitian yang dilakukan oleh Andrews tahun 2009 yang menyatakan bahwa persalinan perabdominal merupan faktor risiko penting untuk terjadinya kolonisasi Staphylococcus aureus pada neonatus dimana disebutkan bahwa bayi yang dilahirkan secara perabdominal memiliki sistem imun yang lebih rendah dibandingkan bayi yang dilahirkan secara normal, sehingga lebih mudah untuk terjadinya kolonisasi bakteri khususnya bakteri Staphylococcus aureus. ${ }^{14}$ Didapatkan hasil yang berbeda dikarenakan faktor utama penyebaran bakteri ialah dari lingkungan rumah sakit dan juga para tenaga medis dirumah sakit tersebut, dimana lamanya bayi dirawat lebih dari 2 hari yang menyebabkan paparan bayi terhadap bakteri yang ada di rumah sakit lebih tinggi, sedangkan sampel yang diambil pada penelitian ini yaitu bayi yang baru lahir dan berada di rumah sakit kurang dari 2 hari.

Penelitian yang dilakukan oleh Tong tahun 2015 juga menyebutkan bahwa bayi yang dilahirkan secara perabdominal atau sectio caesaria memiliki lebih sedikit bakteri alami dari ibunya dibandingkan bayi yang dilahirkan secara normal. Sehingga, besar kemungkinan bayi yang positif terkolonisasi Staphylococcus aureus dari ibu yang melahirkan dengan cara persalinan perabdominal, mendapat bakteri dari lingkungan rumah sakit seperti udara di ruangan, alat-alat medis, dan para tenaga medis si rumah sakit tersebut. ${ }^{15}$

\section{SIMPULAN}

Cara melahirkan merupakan faktor risiko penting terjadinya kolonisasi Staphylococcus aureus pada neonatus dikarenakan terdapat perbedaan hasil kolonisasi bakteri pada neonatus yang dilahirkan melalui jalan lahir (persalinan normal) dan tidak melalui jalan lahir (perabdominal), sehingga dapat disimpulkan terdapat hubungan antara cara persalinan terhadap prevalensi kolonisasi Staphylococcus aureus pada neonatus khususnya di ruang Perinatologi Rumah Sakit lbu dan Anak 
Puri Betik Hati Bandar Lampung.

\section{SARAN}

Berdasarkan penelitian yang telah dilakukan, beberapa saran yang diajukan oleh peniliti ialah harapan kepada masyarakat terutama setiap ibu agar dapat menjaga kebersihan diri guna mengurangi bakteri Staphylococcus aureus di tubuhnya. Untuk para tenaga medis dan fasilitas rumah sakit juga diharapkan menjaga kebersihan dan sanitasi yang lebih baik lagi. Lalu, untuk penelitian selanjutnya diharapkan dapat menggunakan ruang lingkup yang lebih besar, serta fasilitas penelitian yang lebih lengkap.

\section{DAFTAR PUSTAKA}

1. WHO. Region Sepsis and Other Infectious Conditions of Newborn. 2015.

2. Kosim MS. Infeksi neonatal akibat air ketuban keruh. Sari Pediatri. 2009;11(3):212-8.

3. Gordon RJ, Lowy FD. Pathogenesis of methicillin-resistant Staphylococcus aureus infection. Clinical Infectious Dis. 2008; 46(5):350-9.

4. Jawetz E, Melnick J, Adelbergz. Medical microbiology 24th ed. North America: McGraw-Hill. 2007.

5. Chen CJ, Kuang $\mathrm{H}$, Lin TY, Hwang KP, Chen PY, Huang YC, et al. Factors associated with nasal colonization of methicillin resistant Staphylococcus aureus among healthy children in Taiwan. J Clinical Microbiology. 2011; 49(1):131-7.

6. Bourgeois-Nicolaos N, Lucet JC, Daubié C, Benchaba F, Rajguru M, Ruimy R, et al. Maternal vaginalcolonization by Staphylococcus aureus and newborn acquisition at delivery. Paediatric and Perinata; Epidemiology. 2010; 24(5):488-91.

7. Mernelius $S$, Löfgren $S$, Lindgren $\mathrm{PE}$, Matussek A. The role of broth enrichment in Staphylococcus aureus cultivation and transmission from the throat to newborn infants: Results from the swedish hygiene intervention and transmission of $S$. aureus study. European Journal of Clinical Microbiology and Infectious Diseases. 2013; 32(12):1593-8.

8. Cunningham GF. Obstetri Williams ed 21. Jakarta: EGC. 2005.

9. Dewi Y. Manajemen stres, cemas: Pengantar dari a sampai z. Jakarta: Edsa Mahkota. 2007.

10. Sollid JU, Furberg AS, Hanssen AM, Johannessen M. Staphylococcus aureus: determinants of human carriage. Infect Genet Evol. 2014; 21(1):531-41.

11. Almeida GCM, Santos MMD, Lima NGM, Cidral TA. Prevalence and factors associated with wound colonization by Staphylococcus spp. and Staphylococcus aureus in hospitalized patients in inland northeastern Brazil: a crosssectional study. BMC Infectious Diseases. 2014; 14(1):328-9.

12. Notohatmodjo P. Faktor risiko kolonisasi Staphylococcus aureus pada neonatus. Jurnal Kedokteran Diponegoro. 2011; 45:1-23.

13. Dahlman D, Jalalvand F, Blome MA. High perineal and overall frequency of Staphylococcus aureus in people who inject drugs, compared to noninjectors. Curr Microbiol. 2017; 74(2): 159-167.

14. Andrews JI, Fleener DK, Messer SA, Kroeger JS, Diekema DJ. Screening for Staphylococcus aureus carriage in pregnancy: usefulness of novel sampling and culture strategies. American Journal of Obstetrics and Gynecology. 2009; 201(4):391-5.

15. Tong SY, Davis JS, Eichenberger E, Holland T, Fowler VG. Staphylococcus aureus infections: Epidemiology, pathophysiology, clinical manifestations, and management. Clinical Microbiology Reviews. 2015; 28(3):603-61. 